\title{
SYNTHESIS, CHARACTERISATION AND ANTIMICROBIAL EVALUATION OF THE ALKYD RESINS DERIVED FROM CASTOR SEED OIL
}

\author{
Umar, B.Y. ${ }^{1}$, Haruna, Musa ${ }^{2}$ and Sharif, N. Usman ${ }^{3}$ \\ ${ }^{1}$ Science and Technical Schools Board Kano, Kano Nigeria \\ ${ }^{2}$ Department of Pure and Industrial Chemistry, Bayero University, Kano, Kano Nigeria \\ ${ }^{3}$ Department of Chemical Sciences, Federal University, Kashere, P.M.B 0182 Gombe Nigeria
}

\section{ABSTRACT}

Quantity of castor seed oil (CSO) obtained from local market was determined based on acid value, percentage free fatty acid, iodine value, refractive index, saponification number, specific gravity and moisture content. The CSO was employed in the preparation of alkyd resin (oil modified ester) using monoglyceride method. This involved the reaction of the oil with glycerol (alcoholysis) and subsequent reaction of the monoglycride obtained with phthalic anhydride to form the alkyd resin. The CSO and its corresponding alkyd resin were characterized using FTIR. The antimicrobial activity of the alkyd resin was evaluated using paper disc diffusion method. The result showed that prepared alkyd resin is active is active against some selected bacterial srains at concentrations $50 \mathrm{mg} / \mathrm{ml}$ and $100 \mathrm{mg} / \mathrm{ml}$ on E. coli, Sallmonella and Staphylococcus

Keywords: Alkyd resin, Castor Seed Oil, Phthalic anhydride

\section{INTRODUCTION}

Castor Seed Oil (CSO)

Castor bean is cultivated for the seeds which yield viscous, pale-yellow, non volatile and non-drying oil. It has been used for industrial and medicinal purposes (Stubiger et al., 2003). Its botanical name is Recinus communis $L$ of the family Eurphobiace as a plant indigenous to many part of the world (Salimon et al., 2010). It has been reported that its modification by severe dehydration resulted in an oil with excellent drying properties for use in the production of alkyd resin (Onukwli et al., 2008).

Alkyds are oil modified polyesters consisting of a polyol (usually glycerol, trimethalol propane or pentaerythritol), a multi functional acid (phthalic acid or trimellitic acid) and an unsaturated fatty acid formed by polycondensation reaction. They are classified as short (30 - 42\%), medium (43 - 54\%), long (55 $68 \%$ ) and very long ( $268 \%)$, based on the percent weight fraction of vegetable oil in the resin (Manawwer et al., 2014).
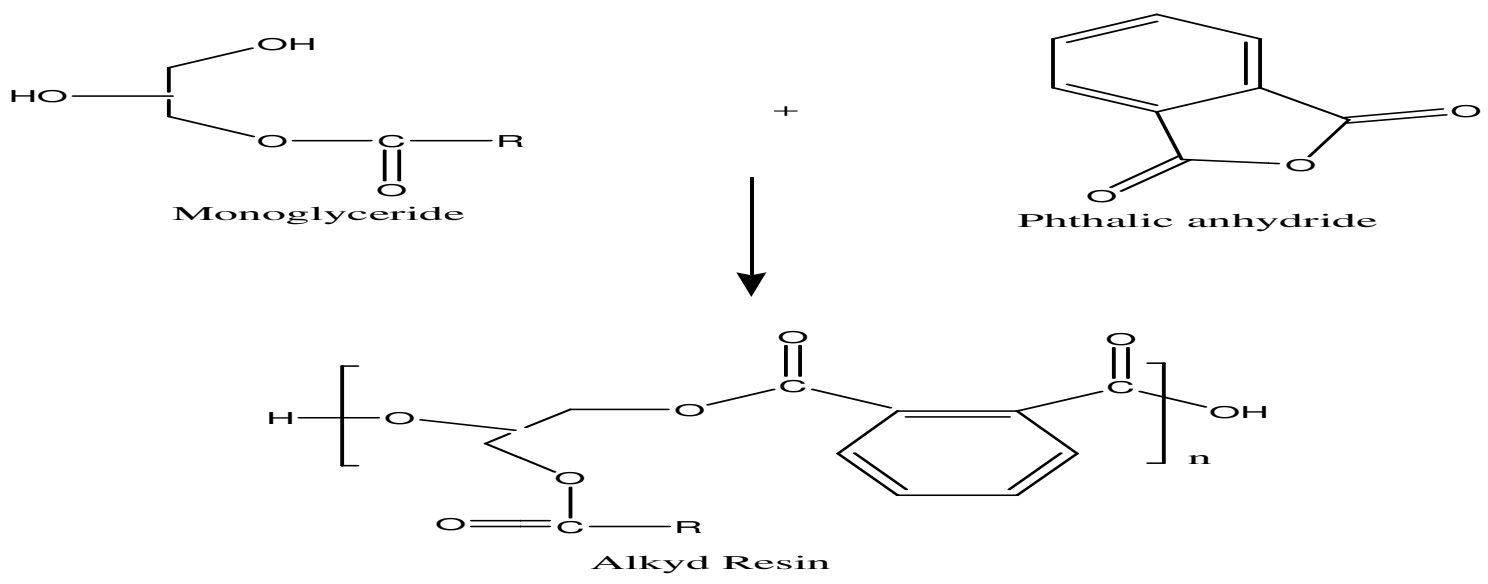

Fig 1:Chemical transformation of vegetable oil to alkyd

\section{MATERIALS AND METHODS}

Castor seed oil was purchased from Kasuwar Kurmi market in Kano city, Kano Nigeria. All chemicals and solvents used were of analytical grade and were used without further purification. The glass wares used were washed with detergent, rinsed with distilled water and dried before used. All weighings were carried out on an electric Mettler balance model H30AR, iodine value, saponification number, acid value, percentage free fatty acid, specific gravity were carried out using burrette, 
standard laboratory apparatus. FTIR spectral analysis of the castor seed oils and alkyd resin samples were recorded in the range of 4000 $650 \mathrm{~cm}^{-1}$ using CAREY630 machine, Antimicrobial activity studies were carried using petri dishes in an incubator.

\section{Physico-Chemical Characterization of Castor Seed Oil}

The physico-chemical properties of the castor seed oil sample including: refractive index, iodine value, saponfication number, acid value, percentage free fatty acid and specific gravity analysis were determined in accordance with the American Oil Chemists Society (AOCS),

\section{Synthesis of the Castor Seed Oil Alkyd Resin}

The measured oil sample (castor seed oil) was poured into the three necked flask and heated to about $120^{\circ} \mathrm{C}$ to expel moisture. A glycerol was added and the temperature was to $230^{\circ} \mathrm{C}$. After 30 minutes an aliquot of the reaction mixture was checked for solubility in methanol, a test for the formation of monoglyceride. The temperature was then lowered to about $180^{\circ} \mathrm{C}$, followed by addition of phthalic anhydride was added, and subsequent addition of about $120 \mathrm{ml}$ xylene $(120 \mathrm{ml})$ into the reaction mixture to aid the removal of water of esterification by forming an azeotrope. The temperature was gradually increased between $240-250^{\circ} \mathrm{C}$ and maintained for about 4 hours. Aliquots were taken from the reaction mixture at intervals of one hour to check for drop in acid value. The reaction was quenched by immersing the reaction vessel in cold water. Nitrogen was used to blanket the surface of the reaction mixture during the reaction (Onukwli et al., 2008).

Physico-chemical characterisation of the alkyd resin

The physicochemical properties of the alkyd resins prepared from the castor seed oils; such as colour, viscosity, acid value and FTIR spectral analysis were determined using American oil chemists society methods (AOCS, 1996).

\section{Antimicrobial Activity of Alkyd Resin}

The antimicrobial activity was carried out by employing agar disc diffusion method (Afroditi, 1996), the suspension of the test bacteria which were spread in the nutrient agar plates were incubated with test organisms for 24 hours at $37{ }^{\circ} \mathrm{C}$ (E. coli, Salmonella, Staphlococcus). One disc from each sample was placed in the petri-dishes with sterile forceps (Karigar et al., 2010). Clear inhibition zones around the disc indicating the presence of antimicrobial activity was recorded.

\section{RESULTS AND DISCUSSION}

The Physico-Chemical Characterization of the Castor Seed Oils

Table 2 showed the results for the physico chemical characterizations of the castor seed

The results of the physical and chemical properties of the oils are shown in Table 2 . The iodine value is 87.613 for CSO, which is less than 100 , hence, the CSO is of lower degree of unsaturation (Ayo et al., 2007). The result shows that the castor seed oil had saponification value of 169.34 which is found to be slightly lower than the range reported by Ogunniyi (2006) i.e $177-182 \mathrm{mg} / \mathrm{g}$. The acid value of the castor oil was found to be 12.04 . Acid value is the measure of the extent to which the constituents' glycerides have been decomposed by lipase action, and has shown to be a general indication of the edibility of the oils (AOAC, 1980; Pearson, 1981). However, the refractive index of the oil is found to be 1.4604 , the values is within the range of edible oils (Rossell, 1991). The specific gravity for the oil are: 0.9080 , which implies that castor seed oil is less dense than water (Momodu et al, 2011). The percentage free fatty acid of the castor seed oil as shown in Table 2 is $7.023 \%$. Also, the percentage moisture content of the oil is found to be high up to $9 \%$. This is probably due to impurities contained that could cause hydrolysis of the ester linkages, thereby increasing the free fatty acid level (Nkafamiya et al; 2010).

Table 1: Formulations of the different alkyd resins

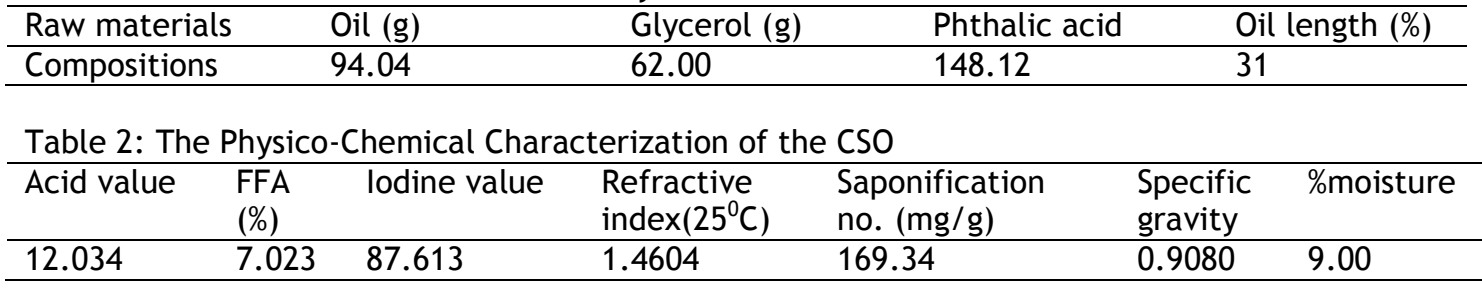


The Physico-Chemical Characterisation of the Alkyd Resins

Table 3 shows the physico-chemical properties of the alkyd resin prepared. The colour of the alkyd is dark brown compared to its corresponding precursor oil.
The darkening in the colour of the alkyds could be attributed to the high temperature of the reaction, oxidation and the catalyst (MacDonald, et al., 1994). The acid value and viscosity of the alkyd is lower compared to the commercial standards C-AKD and L-AKD (Shaker et al., 2012).

Table 3: The Physico-Chemical Properties of Alkyd Resins

\begin{tabular}{|l|c|c|c|}
\hline Properties & CSO-resin & C-AKD & L-AKD \\
\hline Colour & Dark Brown & Brown & Brown \\
Acid value $(\mathrm{mg} / \mathrm{g})$ & 11.00 & 25.80 & 35.60 \\
Viscosity $(\mathrm{cp})$ & 3.84 & 10.00 & 12.80 \\
\hline
\end{tabular}

Antimicrobial Evaluation of the CSO Alkyd Resin

From Figure 1 the antimicrobial activity test for the castor seed oil modified alkyd resin (CSO Resin) determined showed that the resin was active against all the tested organisms at all concentration.

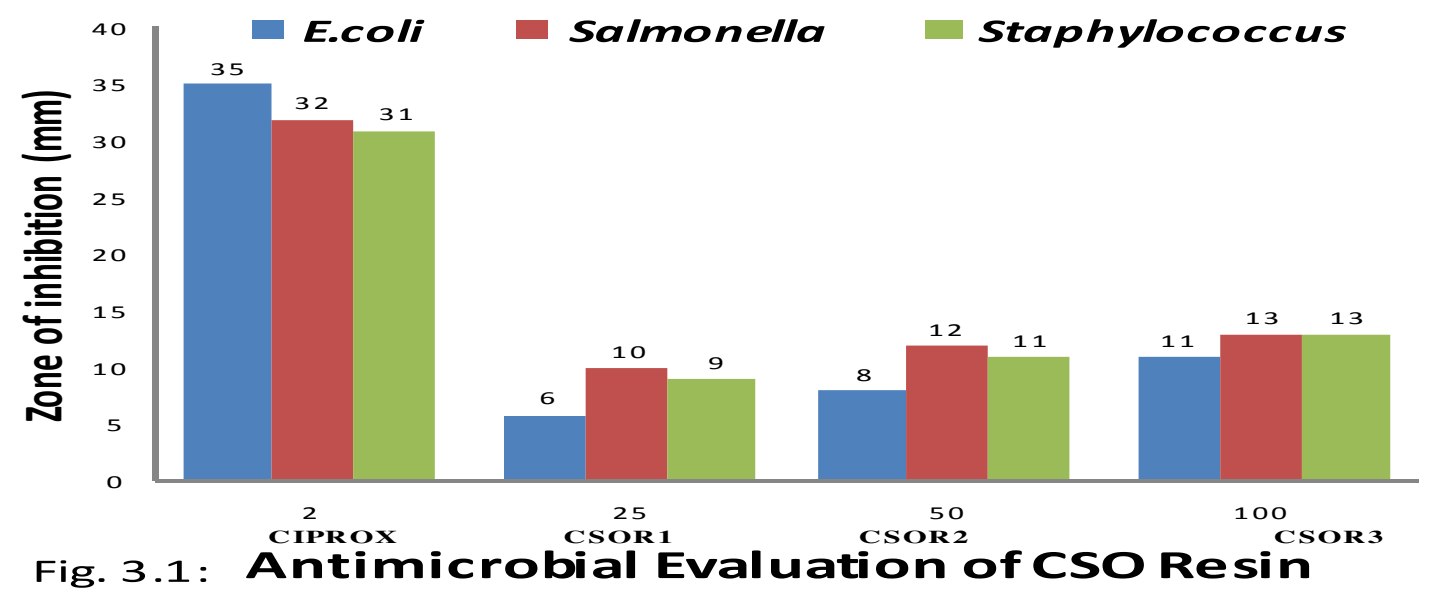

Ciprox $=$ ciproflaxin with conc. $2 \mathrm{mg} / \mathrm{ml}$, CSOR1 $=$ CSO resin with conc. $25 \mathrm{mg} / \mathrm{ml}$ CSOR2 $=$ CSO resin with conc. $50 \mathrm{mg} / \mathrm{ml}$, CSOR3 $=$ CSO resin with conc. $100 \mathrm{mg} / \mathrm{ml}$

\section{FTIR Absorption analysis}

The FTIR analysis for alkyd resins derived from castor seed oil is shown on Table 4.

Table 4 and Fig. 2 show FTIR spectra and peaks of interest for castor seed oil alkyd resin (CSOResin). From the table, it can be observed that the $\mathrm{OH}$ group from the glycerol (Fig.3.1) disappears in the spectrum of the CSO-Resin
(Fig. 2). While, the appearance of the absorption band at $1601 \mathrm{~cm}^{-1}$ indicates the presence of $\mathrm{C}=\mathrm{C}$ stretching for an aromatics from the phthalic anhydride. Other band of interest that was found in the spectrum is the $1728 \mathrm{~cm}^{1}$ which corresponds to $\mathrm{C}=0$ stretching for an ester.

Table 4:

FTIR Absorption Frequencies of Castor Seed Oil Alkyd Resin (CSO Resin)

Bands $\left(\mathrm{cm}^{-1}\right)$
1723
1728
1601

FTIR Peak origin

$\mathrm{C}=0$ Stretching due to conjugation with aromatics

$\mathrm{C}=\mathrm{O}$ Stretching for an ester

$\mathrm{C}=\mathrm{C}$ Stretching for aromatics 


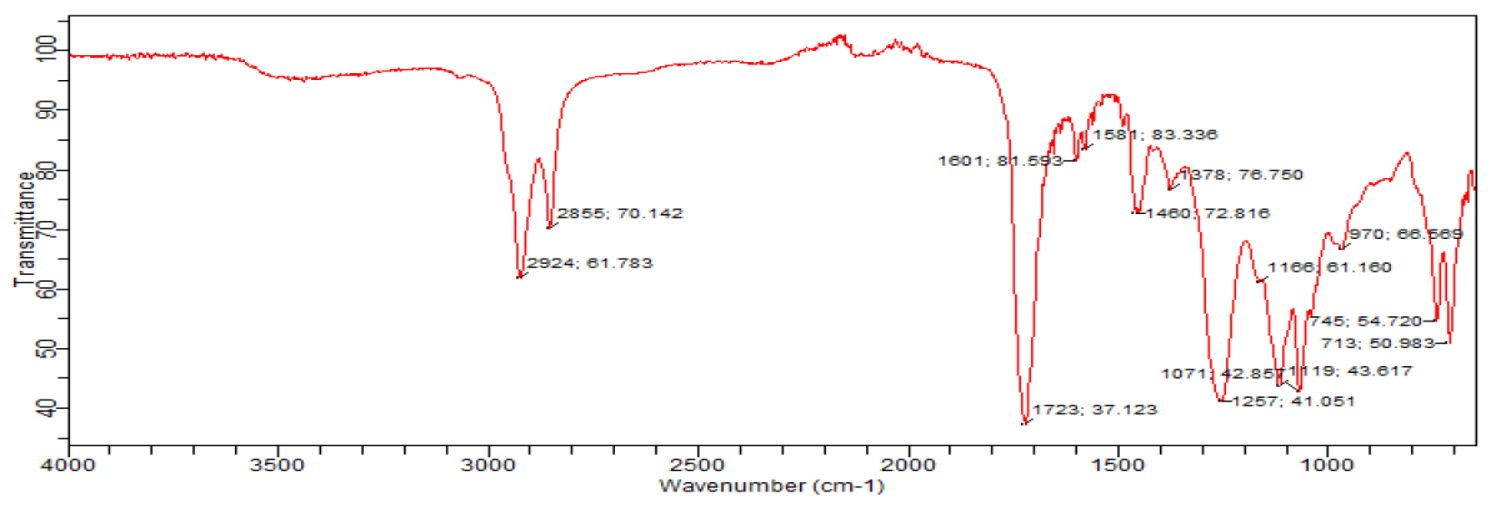

Fig 2: FTIR of castor seed oil alkyd resin (CSO resin)

\section{CONCLUSION}

The results obtained from this study show that the castor seed oil has been successfully

\section{REFRENCES}

Afroditi, S., Eleni, P., Costantina, N., Stella, K., Thomas, L., and Minas, A., (1996). Antimicribial and Cytotoxic activities of originum essential oils. J. Agric. Food Chem. 44(5), 1202-1205.

AOCS, (1996) Sampling and analysis of commercial fats and triglycerides Official methods of Analysis of the American Triglycerides chemist SOC., pp 801-855.

MacDonald, P., Edward, R.A. and Greenhalg, J.P.D. (1994). Animal nutrition $4^{\text {th }}$ edition, longman publishers, pp 22-28, 32-36.

Manawwer A., Deewan A., Aram S., Fahmina Z and Sharif A. (2014). Vegetable oil based eco-friendly coating materials: A review article. Arabian journal of chemistry vol.7Pp. 469-479.

Momoh A. O. Oladunmoye M.K and Adebohi T.T (2012) Evaluation of the antimicrobial and phyto-chemical properties of oil from castor seeds (Recinus communis Linn). Bull., Environ, Pharmacol life science. Vol. 1 (10). Pp21-27.

Momodu V.M., Omorogbe S.O., Ikholuria E. U., Obaze E.O and Aigbodion A.I (2011). Synthesis and evaluation of performance characteristics of walnut (Tetracarpidium conophorum) seed oilmodified Alkyd resin. Research. Vol. 3(7). Pp 63-66.

Nkafamiya I.I., Maina H.M., Osemeahon S.A and Modibbo U.U (2010). Percentage oil converted to alkyd resin. The ability of this alkyd resin to show antimicrobial property, suggests that it has some potential for health care applications.

yeid and physicochemical properties of different ground nut species ( Arachis hypoaea ). African Journal of food sci. Vol. 4(7) Pp. 418-421

Ogunbisi M.A, Ogunyemi I.O, and Yussuf A.O (2014). The modification of different vegetable oils for anticorrosive paint. J. Adv. Agric. Biol. 2(1), 33-38

Onukwli O.D and lgbokwe P.K (2008). Production and characterization of castor oil-modified Alkyd resins. J. Engineering and Applied Sciences. Vol. 3(2). Pp 161-165

Ogunnniyi D.S and Njikang G.N ( 1998 ). Industrial utilization of castor oil: Alkyd resin synthesis and evaluation. J. Nig. Soc. of Chem. Engineers 44-51

Salimon J., Dina A.M.N., Nazrizawati A.T., Mohd M.Y and Noraishah A. (2010) Fatty acid composition and physic-chemical properties of Malaysian Castor Beans Recinus communis L. seed oil. Sains Malaysiana Vol. 39(5). Pp 761-764

Shaker N.O., Alian M.A and Elsawy M.M., (2012). Preparation, characterization and evaluation of jojoba seed oilmodified alkyd resins. Pelagia research Library vol. 3(5) Pp :1157-1162

Stubiger, G., Pittenauer, E., Allmaier, G. (2003). Characterisation of Castor oil by on-line and off-line non-aqueous reverse-phase High-performance Liquid Chromatography -Mass Spectrometry (APCI and UV/MALDI). Phytochemical analysis. 14: 337346 